$\xi=$ 頤

\title{
Principal component analysis of rare earth elements in Sechahun iron deposit, central Iran
}

\author{
Mohammadali Sarparandeh ${ }^{1}$, Ardeshir Hezarkhani ${ }^{1 *}$ \\ ${ }^{1}$ Department of mining and metallurgical engineering, Amirkabir university of technology \\ *Corresponding author E-mail: ardehez@aut.ac.ir
}

\begin{abstract}
Principal component analysis (PCA) is a sufficient way for finding the groups of correlated features. In geochemical exploration of precious metals, it helps to cluster the elements. Especially for rare earth elements (REEs), because of multiplicity of parameters, the proposed method helps to have a better interpretation. Geochemical exploration programs aim to find the hidden information about specific element(s), its abundance, its behavior and its relation with minerals and some other elements. REEs are a group of elements with same chemical behavior. However, some chemical characteristics of light rare earth elements (LREEs) and heavy rare earth elements (HREEs) are different. In this study, relationship between these elements was investigated by applying PC analysis method in Kiruna-type iron ore deposit of Se-Chahun in Central Iran. The four first PCs covered the most variances of the REEs. All the elements showed a correlation together with exception of $\mathrm{La}, \mathrm{Ce}, \mathrm{Nd}, \mathrm{Yb}$ and $\mathrm{Y}$. Results of PC analysis are related to the anomaly of Rare earth elements. It can be concluded that in anomalous areas, loadings of the principal components are affected by variance and anomalous content of the elements.
\end{abstract}

Keywords: Central Iran; Geochemical Exploration; Principal Component Analysis (PCA); Rare Earth Elements (Rees); Se-Chahun Deposit

\section{Introduction}

The rare earth elements, lanthanum to lutetium (atomic numbers 57-71), are members of group IIIA in the periodic table and all have very similar chemical and physical properties (Henderson 1984). The REEs are often broken into two groups: light rare earth elements (LREEs) - lanthanum through europium (atomic numbers 57-63) and the heavier rare earth elements (HREEs)—gadolinium through lutetium (atomic numbers 64-71) (Humphries 2013). Yttrium is often grouped with the HREEs because of its similar chemical properties (Samson and Wood 2004). In Kiruna type iron deposit of Se-Chahun, $\mathrm{Ce}, \mathrm{Nd}$ and $\mathrm{La}$ are more abundant among all REEs and almost all the analyzed samples are depleted from Eu and enriched in $\mathrm{Yb}$ and $\mathrm{Y}$. It should be noted that principally, all deposits contain much more LREE than HREE. Most of the deposits have a content of yttrium and other HREE of only a few percentages (Schuler et al. 2011).

Different geological processes and thermodynamic conditions specify the distribution of REEs in various environments, each with its unique pattern. Therefore, the REEs are known as important geochemical tracers for a wide range of geological processes and their abundances, ratios, isotope compositions, and normalized patterns are the important criteria for geochemical exploration studies (Berger et al. 2014, Cole et al. 2014, Tsay et al. 2014). The REEs are mainly concentrated in specific types of rocks and deposits. In addition, they are potentially known as an important by-product of iron oxide-apatite (IOA) deposits (Simandl 2014).

The relationships in a geochemical dataset can be assessed using two approaches: in term of samples (clustering analysis) and in term of variables (i.e. elements). For example, in this regard, Levitan et al. (2015) applied multivariate statistical treatment consisted of hierarchical cluster analysis and principal component analysis (PCA) for analysis of soil geochemical data collected from the Coles Hill uranium deposit, Virginia, USA. PCA is a classic multivariate analysis technique which has been commonly used to examine relationships among variables. Since only the first few PCs possess most of variances of input data sets which are retained for further interpretation, PCA is an efficient tool in reducing dimension of multi-variable data sets (Wang et al. 2014). Sadeghi et al. (2013) used PCA for spatial interpretations of distributions of rare earth elements (REEs) in Sweden using the Forum of European Geological Surveys (FOREGS) geochemical database of topsoil, subsoil and stream sediment compositions. They showed that the light rare earth elements (LREEs) La, Ce, Nd and $\mathrm{Sm}$ have good correlations among each other but not with $\mathrm{Eu}$, and the heavy rare earth elements (HREEs) including Tb, Dy, Ho, Er, Tm, Yb and Lu also show good correlations among each other but not necessarily with the LREEs. Successful results of this study lead us to use PCA for evaluation of REEs relationships in Se-Chahun iron deposit which is prone to REEs.

\section{General settings of study area}

There are significant concentrations of iron ore in central and north east of Iran. Magnetite is the main mineral in most of important iron ore bodies. Obtrusive elements are often phosphorus and sulfur in the form of apatite, pyrite and seldom chalcopyrite. Iron deposits of Iran can be divided into two main groups: magmatogene and volcano sediments. In most iron ore deposits of Iran, metasomatism is the main reason of concentrating (NISCO 1975). Systematic exploration work during the 1960s and 1970s outlined 34 zones of aeromagnetic anomalies between Bafq in the south to Saghand in the north with a total reserve of more than $1500 \mathrm{Mt}$ iron ore (Torab 2008). Moore and Modabberi (2003) suggested that the separation of an iron oxide melt and the ensuing hydrothermal processes dom- 
inated by alkali metasomatism, were both involved to different degrees in the formation of Choghart and other similar deposits in Central Iran. The Se-Chahun deposit is composed of two major groups of ore bodies called the X and XI anomalies (NISCO 1975). Anomaly X containing $11 \mathrm{Mt}$ iron ore reserve with mainly rich magnetite ore (Torab 2008). Anomaly XI occurs $3 \mathrm{~km}$ northeast of anomaly X. Each anomaly consists of two or three smaller tabular to lens shaped ore bodies in association with other small bodies (Bonyadi 2011). The mineralization is mainly hosted by metasomatized tuffs of andesite composition. Host rocks are known as metasomatites in this deposit (NISCO 1975). Satellite image of this anomaly along with samples' locations and simplified geological map are shown in Fig. 1 and Fig. 2. Ore bodies are comprised of high magnetite ore with grade of up to $67 \%$ (Bonyadi et al. 2011) Host rocks are a series of volcano-sedimentary rocks which are affected by metamorphism and metasomatism and are mainly composed of actinolite and feldspar.

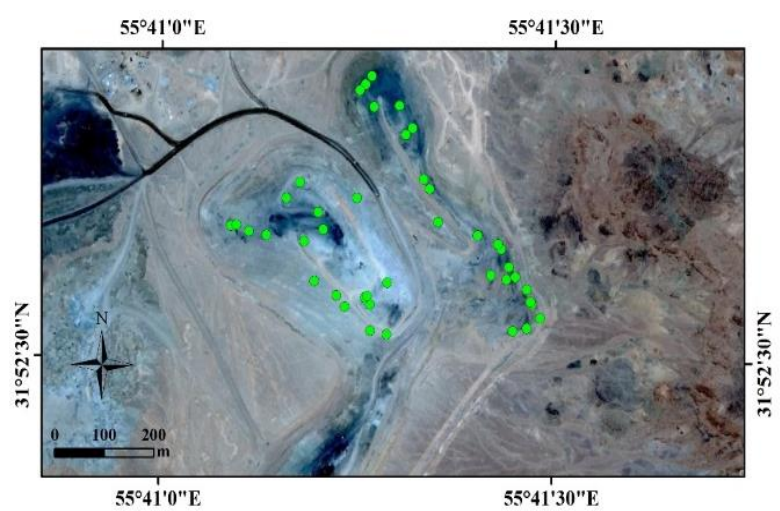

Fig. 1: Satellite Image of Anomaly X of Se-Chahun. Green Spots are Locations of the Samples.

\section{Methodology and dataset}

The central idea of principal component analysis (PCA) is to reduce the dimensionality of a data set consisting of a large number of interrelated variables, while retaining as much as possible of the variation present in the data set. This is achieved by transforming to a new set of variables, the principal components (PCs), which are uncorrelated, and which are ordered so that the first few retain most of the variation present in all of the original variables (Jolliffe 2002). In addition, PCA has been commonly used to examine relationships among variables (Wang et al. 2014). Despite the apparent simplicity of the technique, much researches are still being done in the general area of PCA, and it is very widely used (Jolliffe 2002). $\mathrm{PC}$ analysis has been applied frequently to process and interpret geochemical data and other types of spatial data (e.g. Harris et al. 1997, Carranza 2008, Grunsky 2010, Cheng et al. 2011, Sadeghi et al. 2013, Levitan et al. 2015).

For an $\mathrm{n} \times \mathrm{p}$ data matrix $\mathrm{X}$ with $\mathrm{p}$ variables $\mathrm{xi}(\mathrm{i}=$ one, $\mathrm{n}), \mathrm{PCs}$ are frequently derived from its covariance matrix $\mathrm{C}(\mathrm{X})$ (Filzmoser et al. 2005). Based on the covariance matrix, the eigenvalues and eigenvectors can be calculated (Wang et al. 2014):

$\operatorname{Det}[\mathrm{C}(\mathrm{X}) \neg-\lambda \mathrm{I}]=0$

$[C(X)-\lambda I] U=0$

Where, "I" is the $p \times p$ identity matrix, and "Det" is the determinant of the matrix formed by $C(X)-\lambda I . \lambda_{j}(j=1,2, \ldots, p)$ is the eigenvalue. It is calculated from the characteristic equation of $\mathrm{C}(\mathrm{X})$, and $\mathrm{U}=\left[\mathrm{a}_{\mathrm{j} 1}, \mathrm{a}_{\mathrm{j} 2}, \mathrm{a}_{\mathrm{jp}}\right]$ is the eigenvector matrix. Each $\mathrm{PC}_{\mathrm{j}}$ can be expressed as a linear combination of the $\mathrm{p}$ variables (i.e., $\mathrm{X}_{1}, \mathrm{X}_{2}, \mathrm{X}_{\mathrm{p}}$ ) as (Wang et al. 2014):

$\mathrm{PCj}=$ aj1 Xone+ aj2 Xtwo+. + ajp Xp PCj= aj1 X1+ aj2 X2+.+ ajp Xp

Where $\mathrm{PC}_{\mathrm{j}}$ is the scores of the $\mathrm{jth} P \mathrm{PC}(\mathrm{j}=$ one, $\mathrm{p})$.

The results of PCA are typically presented witrh biplots, which are two-dimensional plots depicting one $\mathrm{PC}$ on the $\mathrm{x}$-axis and another PC on the y-axis (Levitan et al. 2015). Loadings plots are commonly used for interpreting relations among variables (for example: Sadeghi et al. 2013 or Wang et al. 2014). In this study, using the biplots of PCs (loadings plots), the relationships between the REEs were evaluated. The dataset is the concentrations of REEs in $42 \mathrm{li}-$ thology samples from Kiruna type iron deposit of Se-Chahun, Central Iran. Assayed REEs and some statistical parameters are shown in Table 1. Plot of "chondrite-normalized" values for average concentrations of REEs against the elements were drawn and illustrated in Fig. 3.

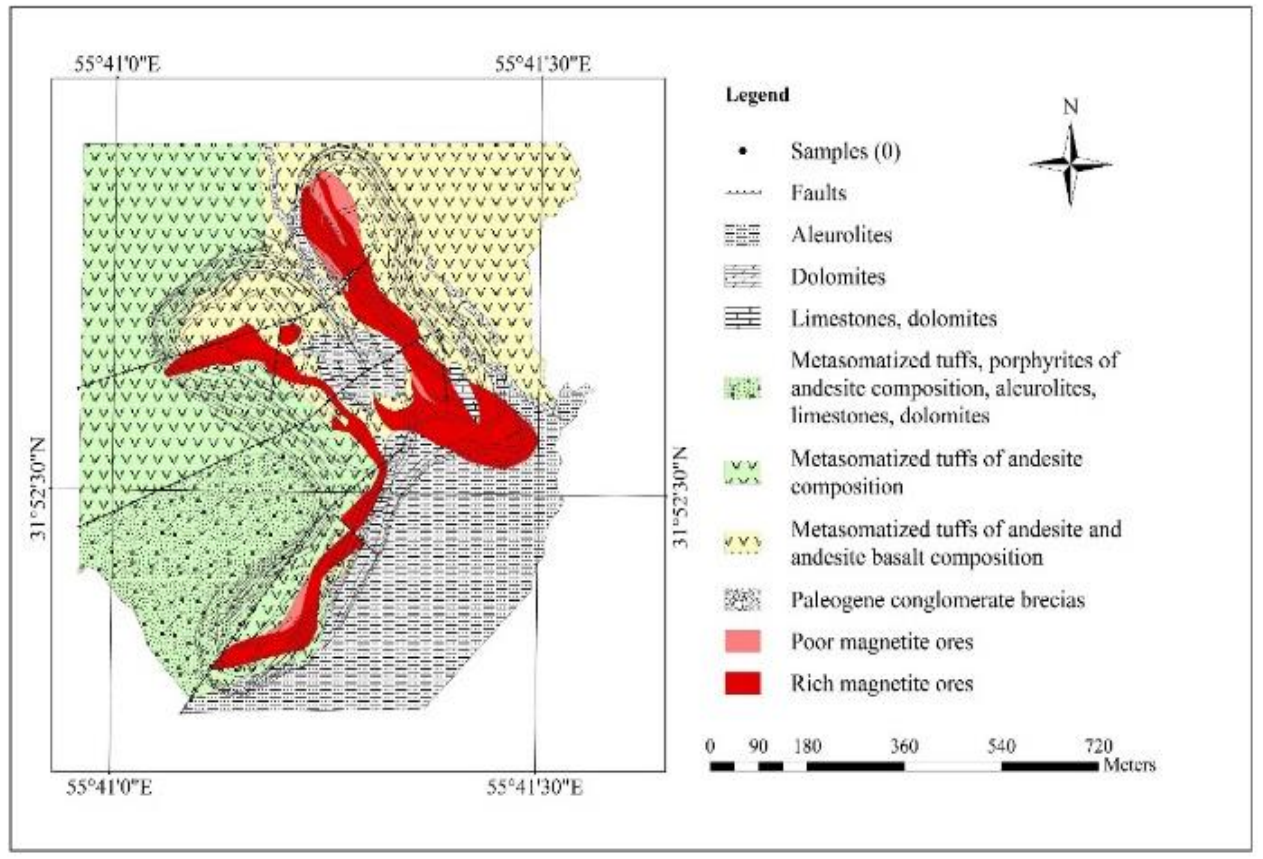

Fig. 2: Simplified Geological Map (Modified After NISCO 1975) of Anomaly X of Se-Chahun. 
Table 1: Assayed Rees and Some Statistical Parameters (42 Samples)

\begin{tabular}{|c|c|c|c|c|c|c|c|c|c|c|c|c|c|c|c|c|}
\hline Elements (ppm) & $\mathrm{La}$ & $\mathrm{Ce}$ & $\operatorname{Pr}$ & $\mathrm{Nd}$ & $\mathrm{Sm}$ & $\mathrm{Eu}$ & Gd & $\mathrm{Tb}$ & Dy & $\mathrm{Er}$ & $\mathrm{Tm}$ & $\mathrm{Yb}$ & $\mathrm{Lu}$ & $\mathrm{Y}$ & $\mathrm{P}$ & $\mathrm{Fe}$ \\
\hline Mean & 73 & 154 & 20 & 75 & 13 & 2 & 13 & 2 & 12 & 7 & 1 & 13 & 1 & 56 & 3723.86 & 26.10 \\
\hline Median & 17 & 49 & 8 & 39 & 8 & 1 & 8 & 1 & 9 & 5 & 1 & 12 & 1 & 39 & 150.5 & 13.84 \\
\hline Variance & 27180 & 111800 & 1202 & 15180 & 299 & 3 & 242 & 4 & 121 & 40 & 1 & 64 & 0 & 2869 & $8.92 * 10^{7}$ & 529.997 \\
\hline Minimum & 3 & 2 & 0 & 5 & 1 & 0 & 1 & 0 & 1 & 1 & 0 & 1 & 0 & 9 & 10 & 0.9903 \\
\hline Maximum & 995 & 2037 & 203 & 740 & 102 & 9 & 90 & 12 & 60 & 32 & 4 & 42 & 3 & 305 & 53400 & 63.29 \\
\hline Skewness & 5 & 5 & 4 & 4 & 4 & 3 & 3 & 3 & 3 & 2 & 2 & 1 & 2 & 3 & 4.122 & 0.21 \\
\hline Kurtosis & 25 & 26 & 20 & 21 & 17 & 13 & 15 & 11 & 9 & 7 & 6 & 3 & 4 & 11 & 19.432 & -1.816 \\
\hline
\end{tabular}

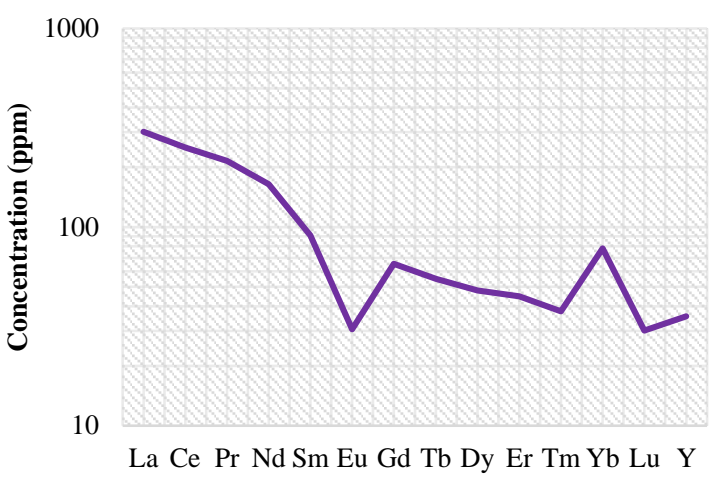

Fig. 3: Chondrite Normalized Rees Distribution (Based on the Average of Rees). Chondrite Values are taken from McDonough and Sun (1995).

\section{Results and discussion}

Principal component analysis makes it possible to find the groups of correlated elements. The first four PCs, cover the most of variances (up to 98\%). Table 2 shows the loadings of PCA for REEs. The first four main PCs are provided in this table.

Table 2: Loadings of PCA for Rees the First Four Main Pcs Are Provided

\begin{tabular}{lllll}
\hline Elements & PC1 & PC2 & PC3 & PC4 \\
\hline $\mathrm{La}$ & 0.406 & -0.276 & -0.275 & 0.644 \\
$\mathrm{Ce}$ & 0.833 & -0.225 & -0.047 & -0.414 \\
$\mathrm{Pr}$ & 0.090 & 0.097 & 0.145 & 0.259 \\
$\mathrm{Nd}$ & 0.322 & 0.481 & 0.709 & 0.240 \\
$\mathrm{Sm}$ & 0.047 & 0.143 & 0.074 & 0.003 \\
$\mathrm{Eu}$ & 0.005 & 0.021 & -0.001 & 0.011 \\
$\mathrm{Gd}$ & 0.043 & 0.147 & 0.008 & -0.014 \\
$\mathrm{~Tb}$ & 0.006 & 0.027 & 0.001 & -0.010 \\
$\mathrm{Dy}$ & 0.031 & 0.172 & -0.041 & -0.046 \\
$\mathrm{Er}$ & 0.017 & 0.116 & -0.010 & -0.029 \\
$\mathrm{Tm}$ & 0.002 & 0.016 & 0.000 & -0.005 \\
$\mathrm{Yb}$ & 0.025 & 0.162 & -0.294 & 0.505 \\
$\mathrm{Lu}$ & 0.001 & 0.013 & -0.002 & -0.005 \\
$\mathrm{Y}$ & 0.154 & 0.720 & -0.552 & -0.174 \\
Eigenvalue & 2833.1 & 326.7 & 85.2 & 36.8 \\
$\mathrm{Cumulative}$ & 84.878 & 94.668 & 97.221 & 98.325 \\
\hline
\end{tabular}

After plotting the first three PCs on the three biplots (Fig. 4), it can be seen that $\mathrm{La}, \mathrm{Ce}, \mathrm{Nd}$ and $\mathrm{Y}$ are separated from other rare earth elements and have anomaly conditions (Fig. 4, a). Moreover, biplots of PC1 and PC2 versus PC3 show the uncorrelation of $\mathrm{Yb}$ with other REEs (Fig. 4, b and c). Other REEs including Pr, Sm, Eu, Gd, $\mathrm{Tb}, \mathrm{Dy}, \mathrm{Er}, \mathrm{Tm}$ and Lu have high correlation with each other (Fig. 4, a, b and c). In addition, unlike the study of Sadeghi et al. (2013) on REEs of topsoil, subsoil and stream sediment of Sweden, there is not a good correlation among LREEs and HREEs in Se-Chahun deposit. As it can be seen in the biplots (Fig. 4), the more variance of an element, the more distant it will be from the rest of the elements. Therefore, loadings are in relation with variances of the elements, in addition to anomalous contents of them.
(A)

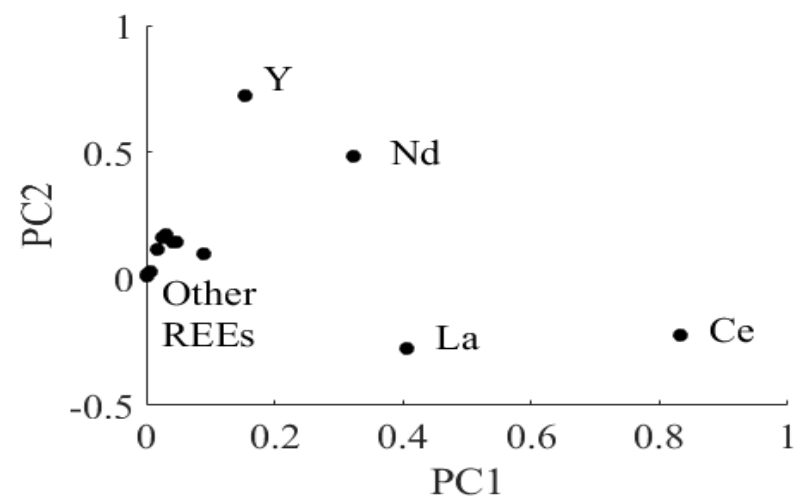

(B)

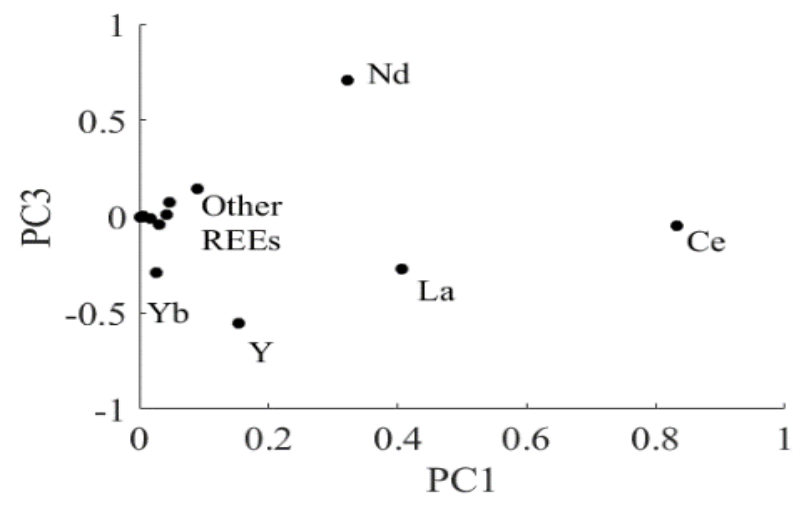

(C)

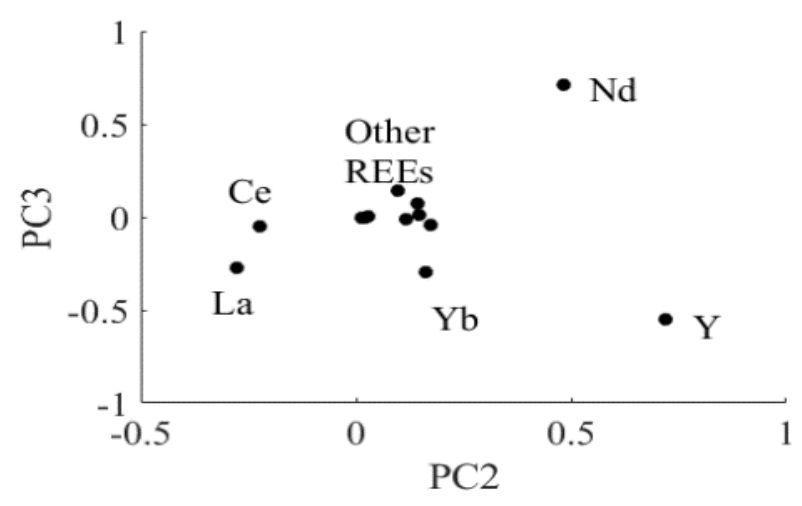

Fig. 4: Principal Component Analysis of Rees (Biplots): (A) PC1 Versus PC2, (B) PC1 versus PC3 and (C) PC2 Versus PC3.

Results of $\mathrm{PC}$ analysis and separations of $\mathrm{La}, \mathrm{Ce}, \mathrm{Nd}, \mathrm{Yb}$ and $\mathrm{Y}$ (Fig. 4) are directly related to the anomaly conditions of these REEs. However, $\mathrm{La}, \mathrm{Ce}$ and $\mathrm{Nd}$ are the most considerable REEs due to their concentrations. 


\section{Conclusion}

There are four main PCs which cover the most variances of REEs. Biplots of the loadings help to find the groups (clusters) of correlated elements. In this study, all REEs were clustered together with exception of $\mathrm{La}, \mathrm{Ce}, \mathrm{Nd}, \mathrm{Yb}$ and $\mathrm{Y}$. These elements were separated far apart other REEs on biplots. Results of PC analysis were related to the anomaly of rare earth elements. Therefore, REEs with anomalous concentrations can be identified on PC biplots. Therefore, unlike the study of Sadeghi et al. (2013) on REEs of topsoil, subsoil and stream sediments of Sweden, there is not a good correlation among LREEs and HREEs in Kiruna-type iron deposit of Se-Chahun. It can be concluded that in anomalous areas, loadings of the principal components are affected by variance and anomalous content of the elements.

\section{Acknowledgements}

We thank the Iranian Mines and Mining Industries Development and Renovation Organization (IMIDRO) for financial support, as well as Iranian Mineral Processing Research Center (IMPRC), Zarazma Mineral Studies Company and Amirkabir University of Technology (Tehran Polytechnic) for laboratory analysis. We also thank the Iran Central Iron Ore Company and the personnel of the mine for their cooperation and contributions to visit the mine and sampling and field operations.

\section{References}

[1] Berger, A., Janots, E., Gnos, E., et al. (2014) Rare earth element mineralogy and geochemistry in a laterite profile from Madagascar. Applied Geochemistry, 41, 218-228. https://doi.org/10.1016/j.apgeochem.2013.12.013.

[2] Bonyadi, Z., Davidson, G.J. Mehrabi, B., Meffre, S., Ghazban, F (2011) Significance of apatite REE depletion and monazite inclusions in the brecciated Se-Chahun iron oxide apatite deposit, Bafq district, Iran: insights from para-genesis and geochemistry. Chemical Geology, 281, 253-269. https://doi.org/10.1016/j.chemgeo.2010.12.013.

[3] Carranza, E.J.M. (2008) geochemical anomaly and mineral prospectivity mapping in GIS. Handbook of Exploration and Environmental Geochemistry, Elsevier, Amsterdam, 11.

[4] Cheng, Q., Bonham-Carter, G.F., Wang, W. et al. (2011) A spatially weighted principal component analysis for multi-element geochemical data for mapping locations of felsic intrusions in the Gejiu mineral district of Yunnan, China. Computers \& Geosciences 5, 662669. https://doi.org/10.1016/j.cageo.2010.11.001.

[5] Cole, C.S., James, R.H., Connelly, D.P. et al. (2014) Rare earth elements as indicators of hydrothermal processes within the East Scotia subduction zone system. Geochimica ET Cosmochimica Acta, 140, 20-38. https://doi.org/10.1016/j.gca.2014.05.018.

[6] Filzmoser, P., Hron, K., Reimann, C. (2005) Principal componen analysis for compositional data with outliers. Environmetrics 20, 621-632. https://doi.org/10.1002/env.966.

[7] Grunsky, E.C. (2010) the interpretation of geochemical survey data Geochemistry: Exploration, Environment, Analysis, 10, 27-74. https://doi.org/10.1144/1467-7873/09-210

[8] Harris, J.R., Grunsky, E.C., Wilkinson, L. (1997) Developments in the effective use of lithogeochemistry in regional exploration programs: application of GIS technology. In: Gubins, A.G. (Ed.), Proceedings of the Exploration'97, Fourth Decennial International Conference on Mineral Exploration, 285-292.

[9] Henderson, P., 1984, Rare earth element geochemistry, Elsevier, Amsterdam.

[10] Humphries, M. (2011) Rare earth elements: The global supply chain, Specialist in energy policy, Congressional research service (https://www.fas.org/sgp/crs/natsec/R41347.pdf)

[11] Jolliffe, I.T. (2002) Principal Component Analysis. Second Edition, Springer, 1-9.

[12] Levitan, D.M., Zipper, C.E., Donovan, P., et al. (2015) Statistical analysis of soil geochemical data to identify pathfinders associated with mineral deposits: An example from the Coles Hill uranium deposit, Virginia, USA. Journal of Geochemical Exploration, 154, 238-251. https://doi.org/10.1016/j.gexplo.2014.12.012.
[13] McDonough, W.F. and Sun, S. (1995) the composition of earth. Chemical geology 120, 223-253. https://doi.org/10.1016/00092541(94)00140-4.

[14] Moore, F., Modabberi, S. (2003) Origin of Choghart iron oxide deposit, Bafq mining district, central Iran: New isotopic and geochemical evidence. Journal of Sciences, 14(3), 259-269.

[15] National Iranian Steel Corporation (1975) Report on detailed exploration of Se-Chahun iron ore deposit in central Iran. Tehran, National Iranian Steel Corporation (NISCO)

[16] Sadeghi, M., Morris, G.A., Carranza, E.J.M. (2013) Rare earth element distribution and mineralization in Sweden: An application of principal component analysis to FOREGS soil geochemistry. Journa of Geochemical Exploration, 133, 160-175. https://doi.org/10.1016/j.gexplo.2012.10.015.

[17] Samson, I.M., Wood, S.A. (2004) Fluid inclusion characteristics and genesis of the fluorite-parisite mineralization in the Snowbird deposit, Montana. Economic Geology, 99, 1727-1744 https://doi.org/10.2113/gsecongeo.99.8.1727.

[18] Schuler, D., Buchert, M., Liu, R., et al. (2011) Study on rare earths and their recycling, Final report for the Greens/EFA group in the european parliament, The Greens/European free alliance, 42-59.

[19] Simandl, G. (2014) Geology and market-dependent significance of rare earth element resources. Mineralium Deposita, 49, 889-904. https://doi.org/10.1007/s00126-014-0546-z.

[20] Torab, F. (2008) Geochemistry and metallogeny of magnetite apatite deposits of the Bafq mining district, Central Iran. Dissertation, Clausthal University of Technology, Germany.

[21] Tsay, A., Zajacz, Z., Sanchez-Valle, C. (2014) efficient mobilization and fractionation of rare earth elements by aqueous fluids upon slab dehydration. Earth and Planetary Science Letters, 398, 101-112. https://doi.org/10.1016/j.epsl.2014.04.042.

[22] Wang, W., Zhao, J., Cheng, Q. (2014) Mapping of Fe mineralizationassociated geochemical signatures using logratio transformed stream sediment geochemical data in eastern Tianshan, China. Journal of Geochemical Exploration, 141, 6-14. https://doi.org/10.1016/j.gexplo.2013.11.008 